\title{
Pengaruh Kepercayaan terhadap Organizational Citizenship Behavior (OCB) dengan Narsisme sebagai Variabel Moderasi pada UMKM Kota Bengkulu
}

\author{
Febzi Fiona*1 \\ Indah Oktari Wijayanti \\ 'Jurusan Manajemen, Fakultas Ekonomi dan Bisnis, Universitas Bengkulu, Indonesia \\ 2Jurusan Akutansi, Fakultas Ekonomi dan Bisnis, Universitas Bengkulu, Indonesia
}

\begin{abstract}
HRM have a role as a thinker, planner, and controller especially in term of Organizational Behaviour. Organizational Citizenship Behavior (OCB) is positive concept which covers an intentions and outcomes, when these behavior have positively effect for organization. Many factors can influence OCB and one of them is trust. The purpose of this study is to examine the effect of trust on OCB and to see the role of narcissism as a moderating variable. The population of this study was all UMKM in Bengkulu city. All data with 80 people were obtained from UMKM Diskopukm Bengkulu City. Sampling collection have been collected using probability random sampling and the data using SPSS as the tool of analyzation. The results of the study were concluded that Trust had a significant positive effect on OCB in UMKM employees in Bengkulu city and narcissism have negatively impact to trust in UMKM employees in Bengkulu city.
\end{abstract}

Keywords: Trust; Organizational Citizenship Behaviour; Narcissism.

\begin{abstract}
Abstrak
HRM berperan sebagai pemikir, perencana, dan pengontrol terutama dalam hal Perilaku Organisasi. Organizational Citizenship Behavior (OCB) merupakan konsep positif yang mencakup maksud dan hasil, ketika perilaku tersebut berpengaruh positif bagi organisasi. Banyak faktor yang dapat mempengaruhi OCB dan salah satunya adalah kepercayaan. Tujuan dari penelitian ini adalah untuk menguji pengaruh kepercayaan terhadap OCB dan untuk melihat peran narsisme sebagai variabel moderasi. Populasi penelitian ini adalah seluruh UMKM di Kota Bengkulu. Seluruh data berjumlah 80 orang diperoleh dari UMKM Diskopukm Kota Bengkulu. Pengumpulan sampel diambil dengan menggunakan probability random sampling dan datanya menggunakan SPSS sebagai alat analisisnya. Hasil penelitian disimpulkan bahwa Trust berpengaruh positif signifikan terhadap OCB karyawan UMKM di Kota Bengkulu dan narsisme berpengaruh negatif terhadap Trust pada karyawan UMKM di Kota Bengkulu.
\end{abstract}

Kata kunci: Kepercayaan; Organizational Citizenship Behaviour (OCB); Narsisme

Article History: Received: (01-10-2020); Revised: (21-10-2020); and Published: (30-10-2020)

Copyright @ 2020 Febzi Fiona, Indah Oktari Wijayanti

How to cite this article: Fiona, F., dan Wijayanti, I. O (2020). Pengaruh Kepercayaan terhadap Organizational Citizenship Behavior (OCB) dengan Narsisme sebagai Variabel Moderasi pada UMKM, Kota Bengkulu. Managament Insight: Jurnal IImiah Manajemen. 15(2), 144-155

Retrevied from: https://ejournal.unib.ac.id/index.php/Insight 


\section{PENDAHULUAN}

Organisasi atau perusahaan saat ini banyak yang krisis tentang kepercayaan, dan lebih senang bekerja secara individu sehingga membuat perilaku pekerja itu sendiri tidak sesuai dengan yang diharapkan perusahaan. Faktor-faktor yang dapat memengaruhi tingkat kepercayaan dalam sebuah perusahaan, salah satunya yaitu perilaku narsisme dari pekerja. Menurut Brummelman et al. (2016), narsisme adalah orang-orang yang merasa lebih unggul dari orang lain, mereka percaya bahwa mereka berhak atas hak istimewa, menginginkan rasa hormat dan kekaguman dari orang lain. Menurut Suhartanti (2016), kepribadian narsistik merupakan kepribadian yang menghayalkan keagungan dirinya kurang dapat berempati, sangat mendambakan untuk dihormati dan tidak dapat melihat berdasarkan sudut pandang orang lain.

Ellison dan Boyd (2013) mengatakan seorang yang memiliki sifat narsisme tidak bisa menerima penilaian dari sudut pandang orang lain, sehingga mereka melihat dirinya lebih baik dari orang lain. Narsisme dalam organisasi baru pertama kali dipertimbangkan sebagai variable moderasi pada hubungan kepercayaan terhadap OCB oleh Yildiz et al. (2012). Hasil dari penelitian tersebut menjelaskan bahwa kepercayaan organisasi berpengaruh positif signifikan terhadap perilaku kewarganegaraan organisasi dan hubungan ini dimoderasi oleh narsisme dengan cara yang negatif. Narsisme menghasilkan hasil yang tidak sehat Karena efek negatif sebagai moderasi. Narsisme pada dasarnya memiliki konsekuensi yang baik ketika organisasi mampu untuk mengelolanya, tetapi sebaliknya, akan berdampak buruk bagi organisasi ketika tidak mampu untuk mengelola perilaku narsisme karyawan. Konsekuensi dari narsisme karyawan tersebut membuat peneliti tertarik untuk menganalisis dan mengetahui hasilnya melalui penelitian pada Usaha Mikro Kecil Menengah (UMKM) di Kota Bengkulu.

Berdasarkan latar belakang dan uraian diatas maka perumusan masalah dalam penelitian ini yaitu Apakah kepercayaan berpengaruh terhadap OCB pada UMKM di Kota Bengkulu dan Apakah narsisme memperkuat atau melemahkan pengaruh antara kepercayaan terhadap OCB pada UMKM di Kota Bengkulu. Tujuan penelitian ini adalah untuk mengetahui pengaruh kepercayaan terhadap OCB pada UMKM di kota Bengkulu dan mengetahui peran narsisme dalam memoderasi pengaruh kepercayaan terhadap OCB pada UMKM di Kota Bengkulu. Penelitian ini diharapkan menjadi salah satu pengetahuan empiris yang baru mengenai OCB (Organizational Citizenship Behavior) di mana etika terbentuk dari dalam diri individu tersebut.

\section{TINJAUAN PUSTAKA}

\section{Kepercayaan (Trust)}

Konsep kepercayaan telah didefinisikan sebagai rasa percaya diri dan komitmen tanpa persepsi ketakutan dan keraguan, seseorang percaya bahwa ia akan menerima dukungan dan kolaborasi dalam memecahkan masalah pada saat dibutuhkan, tanpa 
adanya motif tersembunyi yang mendasari dan atau pikiran negatif pada bagian dari orang lain. Menurut Arshad et al. (2016), menunjukkan bahwa semakin tinggi kepercayaan konsumen maka semakin tinggi pula kepuasan konsumen yang dirasakan.

\section{Dimensi Kepercayaan}

Menurut Shao (2018) terdapat lima dimensi utama yang membentuk konsep kepercayaan yaitu:

1. Integritas, merupakan keyakinan bahwa seorang individu atau organisasi akan melakukan apa yang telah dijanjikan untuk dilakukan dan akan bertindak tanpa kontradiksi.

2. Kompetensi, yaitu mengacu pada kualifikasi individu, berdasarkan keterampilan dan pengetahuan yang dimiliki oleh seorang individu.

3. Konsistensi, memiliki arti bahwa seseorang dapat diandalkan, memiliki kemampuan memprediksi dan mengatasi setiap persoalan

4. Loyalitas, yaitu kesetiaan individu terhadap organisasi yang dimiliki dan memiliki keinginan kuat untuk melindungi dan menjaga satu sama lain dalam organisasi.

5. Keterbukaan, berarti bahwa individu dan organisasi saling berbagi gagasan dan informasi dengan bebas tanpa ada yang disembunyikan.

\section{Organizational Citizenship Behavior (OCB)}

Organizational Citizenship Behavior adalah perilaku individu yang mencerminkan organisasi yang baik, sadar akan hak dan kewajiban terhadap organisasi, membela dan menjaga martabat organisasi tanpa pamrih, patuh dalam menjaga aturan organisasi, menjaga infrastruktur organisasi dan juga berperilaku menuju tingkat standar yang dijunjung tinggi oleh organisasi (Hazanah, 2018).

OCB adalah perilaku karyawan yang mempraktikkan peranan tambahan dan menunjukkan sumbangannya kepada organisasi melebihi peran spesifikasinya dalam pekerjaan, perilaku tersebut merupakan sesuatu yang efektif untuk meningkatkan fungsi sebuah organisasi.

\section{Dimensi OCB}

Organ (1988) dalam Sudarma (2012) mengemukakan lima dimensi primer dari OCB yaitu:

1. Altruism, yaitu perilaku membantu karyawan lain tanpa ada paksaan pada tugastugas yang berkaitan erat dengan operasional organisasi.

2. Courtesy, adalah perilaku meringankan masalah-masalah yang berkaitan dengan pekerjaan yang dihadapi orang lain.

3. Conscientiousness, berisi tentang kinerja dari pra syarat peran yang melebihi standar minimum. 
4. Sportmanship, berisi tentang pantangan-pantangan membuat isu yang merusak meskipun merasa kesal.

5. Civic virtue, menunjukkan partisipasi sukarela dan dukungan terhadap fungsi- fungsi organisasi baik secara profesional maupun sosial alamiah.

\section{Narsisme}

Menurut Suhartanti (2016) individu dengan kepribadian narsistik akan melalukan sesuatu yang berlebih dari orang lain demi mendapatkan ketakjuban dari orang lain yang melihatnya dari penampilan fisik atau hal-hal yang dilakukannya, serta terobsesi untuk menunjukkan kehebatan dan pesona diri dengan melakukan hal yang unik dibandingkan orang lain.

Oleh karena itu, pelaku narsis sangat yakin dan percaya diri atas kemampuan yang mereka miliki dalam domain tugas. Narsisme pada sisi motivasi memiliki kebutuhan yang kuat atas pengakuan orang lain terhadap keunggulan yang dimiliki, hal ini diperoleh dalam bentuk penguatan, tepuk tangan dan sanjungan.

\section{Dimensi Narsisme}

Menurut Gardner dan Pierce (2011) terdapat lima dimensi narsisme yang sering digunakan oleh peneliti,yaitu:

1. Otoritas, yaitu pandangan yang berlebihan terhadap diri sendiri terkait dengan otoritas atau wewenang atas jabatan yang dimilikinya. Individu yang memiliki tingkat otoritas atau wewenang yang tinggi, akan menganggap bahwa dirinya lebih baik daripada individu yang tidak memiliki otorisas atau wewenang di perusahaan atau organisasi tempat individu tersebut bekerja.

2. Superioritas yaitu pandangan berlebihan terhadap diri sendiri terkait dengan kompetensi. latar belakang pendidikan yang tinggi, bakat, kemampuan dan keunikan akan membuat seseorang merasa bahwa dirinya merupakan seorang yang hebat dan spesial.

3. Eksibisionisme, yaitu kecenderungan untuk menarik perhatian orang lain terhadap diri sendiri, terkait dengan kemampuan yang dimiliki, sifat atau kebiasaan, karakteristik maupun keahlian yang dimiliki oleh seseorang.

4. Eksploitasi, yaitu motivasi untuk memanipulasi dan mendayagunakan orang lain untuk kepuasan diri sendiri. Seorang yang memiliki sifat narsisme akan senang untuk mendayagunakan dan memanipulasi orang lain, hal ini dikarenakan narsisis percaya dirinya dapat memahami orang lain dan membuat orang lain percaya dan suka kepadanya

5. Hak, yaitu kepercayaan bahwa orang lain berhutang rasa hormat dan kekaguman. Seseorang yang memiliki sifat narsisme sangat membutuhkan keadaan dimana orang lain memuji dirinya, mengagumi dirinya dan menghormati dirinya. Kebutuhan 
ini yang membuat seorang narsisis menjadi bersikap arogan, ketika kebutuhan tersebut tidak terpenuhi.

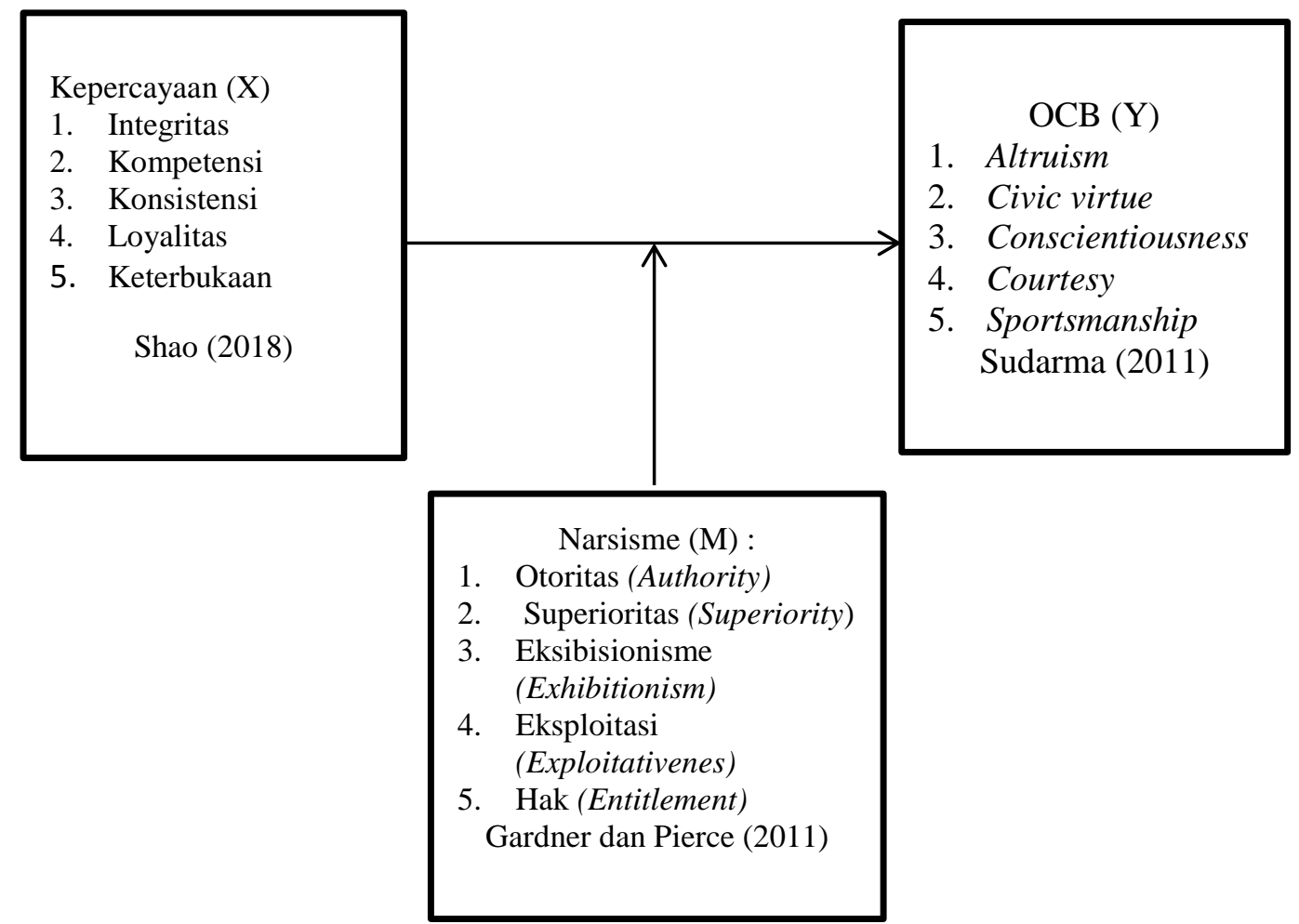

Gambar 1. Kerangka Pemikiran

\section{Hipotesis}

Hipotesis merupakan dugaan sementara terhadap masalah penelitian yang masih perlu diuji kebenarannya melalui penelitian. Hipotesis dalam penelitian ini yaitu $\mathrm{H}_{1} \quad$ : Kepercayaan memiliki pengaruh yang positif dan signifikan terhadap OCB pada UMKM di Kota Bengkulu.

$\mathrm{H}_{2}$ : Narsisme melemahkan pengaruh kepercayaan terhadap OCB pada UMKM di Kota Bengkulu.

\section{METODE PENELITIAN}

Penelitian ini menggunakan metode kuantitatif. Metode kuantitatif adalah penelitian ilmiah yang sistematis terhadap bagian-bagian fenomena yang akan diteliti serta hubungannya. Penelitian ini menggunakan metode kuantitatif karena data yang diperoleh langsung dari responden dan menghindari potensi bias yang sifatnya personal. Penelitian ini menggunakan metode non probability sampling yang artinya teknik yang tidak memberi peluang yang sama bagi setiap unsur atau anggota popusi untuk dipilih menjadi sampel. Teknik pengambilan sampel yaitu sampel jenuh teknik ini digunakan karena populasinya relatif kecil. Jumlah populasi dalam penelitian ini 80 dan seluruh populasi dijadikan sampel. 
Sampel yang diambil untuk kelompok usaha mikro dalam penelitian ini yaitu rumah makan, jasa perbengkelan, konveksi, pangkas rambut dan konter. Sampel untuk kelompok usaha kecil yaitu pada pengrajin industri makanan dan minuman, kemudian sampel untuk kelompok usaha menengah yaitu pada restoran, toko pakaian dan toko elektronik.

Operasionalisasi variabel dalam penelitian ini mengunakan variabel dependen dan independen.Variabel dependen pada penelitian ini adalah OCB. Dimensi yang digunakan pada varibel OCB adalah: 1) altruism, 2) courtesy, 3) sportsmanship dan 3) civic virtue (Organ, 1988). Variabel independen yaitu trust. Dimensi trust yang digunakan untuk mengukur variabel ini adalah: 1) integritas, 2) kompetensi, 3) konsistensi, 4) loyalitas dan 5) keterbukaan (Knight et al., 2000). Variabel Moderasi, variabel moderasi pada penelitian ini adalah narsisme. Demensi dari variabel moderasi adalah: 1) otoritas, 2) superioritas, 3) eksibisionisme, 4) eksploitasi dan 5) hak.

Penelitian ini menggunakan metode kuesioner sebagai metode utama dalam memperoleh data. Skala pengukuran yang digunakan adalah skala Likert yang digunakan memiliki empat tingkatan dengan bobot dan kriteria yaitu (1) sangat tidak sesuai (STS), (2) tidak sesuai (TS), (3) sesuai (S) dan (4) sangat sesuai (SS). Adapun prosedur penelitian yang dilakukan adalah analisis statistik deskriptif, uji asumsi klasik dan uji hipotesis penelitian.

\section{HASIL DAN PEMBAHASAN}

Berdasarkan hasil pengolahan data diperoleh karakteristik responden yang ditampilkan pada table berikut ini.

Tabel 1. Karakteristik Responden

\begin{tabular}{|c|c|c|c|}
\hline Keterangan & & Jumlah (Orang) & Persentase (\%) \\
\hline \multicolumn{4}{|l|}{ Jenis Kelamin } \\
\hline Laki-laki & & 26 & 46 \\
\hline Perempuan & & 30 & 54 \\
\hline TOTAL & & 56 & 100 \\
\hline \multicolumn{4}{|l|}{ Usia } \\
\hline$<25$ Tahun & & 11 & 20 \\
\hline 26-30 Tahun & & 23 & 41 \\
\hline 31-35 Tahun & & 14 & 25 \\
\hline > 36 Tahun & & 8 & 14 \\
\hline TOTAL & & 56 & 100 \\
\hline \multicolumn{4}{|l|}{ Tingkat Pendidikan } \\
\hline SMA & & 37 & 66 \\
\hline D3 & & 5 & 9 \\
\hline S1 & & 12 & 21 \\
\hline S2 & & 2 & 4 \\
\hline & TOTAL & 56 & 100 \\
\hline
\end{tabular}

Sumber : Data Primer Diolah, 2019 
Berdasarkan Tabel 1 diatas, pada penelitian ini diketahui bahwa sebagian besar responden berjenis kelamin Perempuan yaitu sebesar 54\% yang menunjukan bahwa dari sisi jenis kelamin responden dalam mengolah informasi cenderung lebih teliti dengan menggunakan informasi yang lebih lengkap dan mengevaluasi kembali informasi tersebut serta tidak gampang menyerah (Susanti, 2017), berusia diatas 26-30 Tahun yaitu sebesar $41 \%$ yang menunjukkan bahwa dari sisi usia responden berada pada rentang usia yang produktif untuk bekerja. Pendidikan terakhir sebagian besar responden adalah SMA sebesar $66 \%$ yang menunjukkan bahwa pendidikan tidak mempengaruhi dalam dunia bisnis karena mereka bermodal keberanian ketika memulai berwiraswasta.

Adapun hasil uji validitas dan relibilitas pada penelitian ini masing-masing data dalam penelitian ini dapat dilihat pada Tabel berikut:

Tabel 2. Hasil uji validitas intrumen

\begin{tabular}{|c|c|c|c|c|}
\hline NO & Variabel & KMO MSA & Signifikan & Keterangan \\
\hline 1 & Kepercayaan & 0,652 & 0,000 & Valid \\
\hline 2 & $\mathrm{OCB}$ & 0,686 & 0,000 & Valid \\
\hline 3 & Narsisme & 0,693 & 0,000 & Valid \\
\hline
\end{tabular}

Sumber : Data Primer Diolah, 2019

** adalah nilai signifikansi dibawah 0,01 (1\%)

* adalah nilai signifikansi dibawah 0,05 (5\%)

Tabel 3. Hasil uji Reliabilitas

\begin{tabular}{llccc}
\hline No & Variabel & Jumlah Instrumen & $\begin{array}{c}\text { Nilai Alpha } \\
\text { Cronbach }\end{array}$ & Ket. \\
\hline 1. & Kepercayaan & 10 & 0,753 & Reliabel \\
2. & OCB & 10 & 0,703 & Reliabel \\
3. & Narsisme & 10 & 0,821 & Reliabel \\
\hline
\end{tabular}

Sumber: Data Primer Diolah 2019

Berdasarkan hasil pengolahan yang dilakukan sebagaimana terangkum pada Tabel 3 diperoleh hasil bahwa nilai Cronbach's alpha pada variabel kepercayaan 0,753 OCB 0,703 Narsisme 0,82. Variabel kepercayaan, OCB dan narsisme Cronbach's alpha lebih besar dari 0,70 jadi tidak ada masalah pada uji realibilitasnya. Dengan demikian dapat disimpulkan bahwa seluruh instrumen atau variabel penelitian adalah reliabel

Pengumpulan data penelitian dilaksanakan mulai tanggal 17 Juni 2019 sampai dengan 31 Juni 2019. Data dikumpulkan dengan cara mengirim kuesioner secara langsung kepada responden. Seluruh kuesioner yang kembali dalam penelitian ini di jadikan sampel. 
Tabel 4. Pengumpulan Data

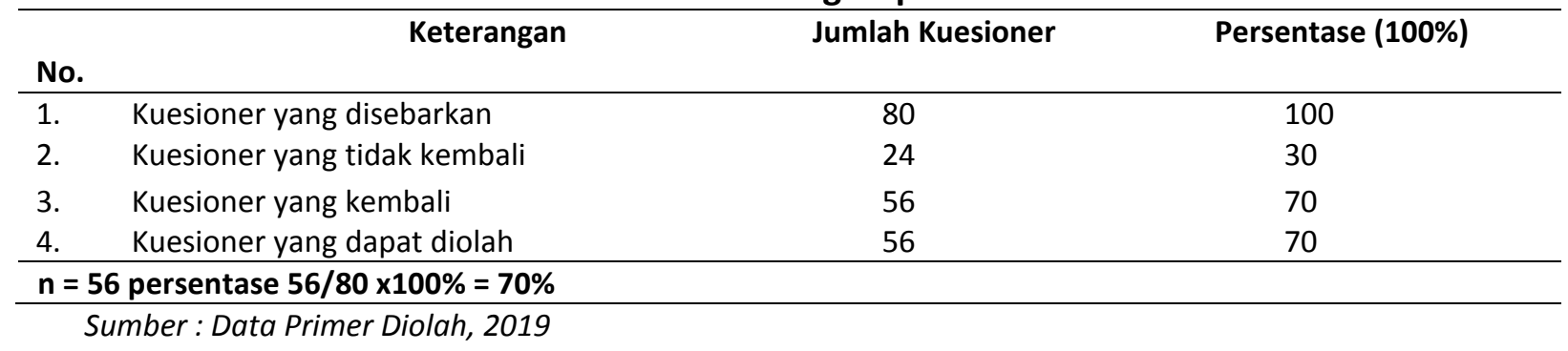

Dari Tabel 4 dapat dilihat kuesioner yang disebarkan di UMKM Provinsi Bengkulu 80 kuesioner, kuesioner yang tidak kembali berjumlah 24 kuesioner atau $30 \%$, penyebab tidak kembalinya kuesioner tidak memberi kabar lebih lanjut. Tingkat pengambilan kuesioner adalah $70 \%$, yang berarti kuesioner yang dikembalikan sejumlah 56 kuesioner. kuesioner yang dapat diolah hanya 56 dengan responden rate $70 \%$.

\section{Statistik Deskriptif}

Semua kuesioner yang telah terkumpul ditabulasi untuk tujuan analisis data. Data yang ditabulasi adalah keseluruhan jawaban dari responden. Pertanyaanpertanyaan berkaitan dengan variabel Kepercayaan, OCB dan narsisme. Data hasil tabulasi diolah menggunakan program SPSS versi 23 yang menghasilkan deskripsi statistik variabel penelitian seperti yang ada pada Tabel 2.

Tabel 5. Statistik Deskriptif

\begin{tabular}{|c|c|c|c|c|c|c|c|c|}
\hline \multirow{2}{*}{ Variabel } & \multirow{2}{*}{$\mathbf{N}$} & \multicolumn{3}{|c|}{ Kisaran Teoritis } & \multicolumn{3}{|c|}{ Kisaran Aktual } & \multirow{2}{*}{$\begin{array}{c}\text { Std. } \\
\text { Deviation }\end{array}$} \\
\hline & & Min & Maks & Mean & Min & Maks & Mean & \\
\hline Kepercayaan & 56 & 9 & 45 & 27 & 31 & 45 & 38,35 & 3,338 \\
\hline OCB & 56 & 8 & 40 & 24 & 29 & 40 & 34,15 & 2,883 \\
\hline Narsisme & 56 & 12 & 60 & 36 & 38 & 59 & 48,84 & 5,226 \\
\hline
\end{tabular}

Sumber: Data Primer Diolah 2019

Berdasarkan dari Tabel 5 menunjukkan bahwa variabel Kepercayan memiliki nilai mean aktual 38,35 lebih besar daripada nilai mean teoritis 27, ini berarti bahwa secara rata-rata UMKM kota Bengkulu sudah mempunyai Kepercayaan yang tinggi. Standar deviasi untuk variabel $\mathrm{i}$ adalah 3,338 lebih kecil dari nilai rata-rata dengan kisaran aktual. Hal ini mengindikasikan bahwa tidak terjadi variasi data penelitian pada variabel kepercayaan dan jawaban responden cenderung bersifat homogen.

Variabel OCB memiliki nilai mean aktual yang lebih besar yaitu 34,15 dan nilai mean teoritis 24, ini berarti bahwa secara rata-rata UMKM Provinsi Bengkulu sudah mempunyai OCB yang tinggi. Standar deviasi variabel OCB adalah 2,883 lebih kecil dari 
nilai rata-rata dengan kisaran aktual. Hal ini mengindikasikan bahwa tidak terjadi variasi data penelitian pada variabel independensi dan jawaban responden cenderung bersifat homogen.

Variabel Narsisme memiliki nilai mean aktual 48,84 lebih besar dari nilai mean teoritis 36 ini berarti bahwa secara rata-rata UMKM Provinsi Bengkulu sudah mempunyai Narsisme yang tinggi. Standar deviasi ini menunjukkan ukuran variasi data terhadap nilai mean (jarak rata-rata). Standar deviasi untuk variabel narsisme adalah 5,226 lebih kecil dari nilai rata-rata dengan kisaran aktual. Hal ini mengindikasikan bahwa tidak terjadi variasi data penelitian pada variabel narsisme dan jawaban responden cenderung bersifat homogen.

\section{Pembahasan}

Penelitian yang dilakukan oleh Yildiz et al. (2012) merupakan penelitian pertama tentang "Narcissism as a Moderator of the Relationship between Organizational Trust and Organizational Citizenship Behaviour." Penelitian yang pertama menggunakan narsisme sebagai variabel moderasi. Survei penelitian ini dilakukan pada 190 karyawan berbagai perusahaan di Turki. Data yang diperoleh dari kuesioner dianalisis melalui SPSS paket perangkat lunak statistik. Hasil Analisis menunjukkan bahwa kepercayaan organisasi berpengaruh positif signifikan terhadap perilaku kewarganegaraan organisasi, dan hubungan ini dimoderasi oleh narsisme dengan cara yang negatif. Pembaharuan pada penelitian ini mengangkat apakah kepercayaan yang berpengaruh terhadap OCB pada UMKM di Kota Bengkulu dan mencari tahu narsisme memperkuat atau melemahkan pengaruh kepercayaan terhadap OCB pada UMKM di Kota Bengkulu.

Sumbangsih untuk ilmu, diharapkan menjadi salah satu pengetahuan empiris yang baru mengenai OCB (Organizational Citizenship Behavior) di mana etika terbentuk dari dalam diri invidu tersebut.

\section{Pengaruh Kepercayaan terhadap OCB}

Hipotesis pertama menyatakan bahwa kepercayaan berpengaruh positif terhadap OCB secara statistik hipotesis ini diterima. Hal ini berarti UMKM di Kota Bengkulu yang memiliki kepercayaan tentu akan melakukan tindakan OCB dengan baik. Hasil penelitian menunjukkan Kepercayaan merupakan bagian terpenting untuk interaksi organisasi yang sukses dengan melibatkan seluruh SDM yang ada, supaya dapat membangun hubungan kerja yang saling percaya satu dengan yang lain (Debora, 2007).

Kepercayaan berdampak positif pada peningkatan motivasi, Organizational Citizenship Behavior (OCB), komitmen dan kepuasan kerja organisasi (Altuntas \& Baykal, 2010; (Fiona, 2018)). Menurut Robbins dan Judge (2010), OCB adalah perilaku atas kehendak diri sendiri yang bukan menjadi bagian tuntutan kerja formal tetapi Fiona dan Wijayanti

Pengaruh Kepercayaan terhadap Organizational Citizenship Behavior (OCB) dengan Narsisme sebagai Variabel Moderasi pada UMKM, Kota Bengkulu 
mendorong efektivitas fungsi organisasi. OCB menjelaskan nilai tambah pada karyawan yang merupakan salah satu bentuk perilaku prososial, yaitu perilaku social positif, konstruktif dan bermakna (Aldag \& Reschke, 2007).

Istilah OCB digunakan untuk mengidentifikasikan perilaku anggota organisasi sehingga individu dapat disebut anggota yang baik. Perilaku ini lebih cenderung melihat seseorang sebagai makhluk sosial, bukan sebagai mahluk individual yang mementingkan dirinya sendiri.

\section{Pengaruh Kepercayan terhadap OCB dengan Narsisme sebagai pemoderasi}

Hipotesis kedua menyatakan bahwa kepercayan terhadap OCB dengan narsisme sebagai pemoderasi secara statistic, hipotesis ini diterima. Hal ini berarti UMKM Kota Bengkulu yang memiliki Narsisme melemahkan pengaruh kepercayaan terhadap OCB. Hasil penelitian sesuai dengan Godkin dan Allcorn (2009) yang menyatakan narsisme seseorang berada pada kisaran baik dan tidak baik. Individu dengan narsis baik ditandai dengan bakat intelektual yang dikombinasikan oleh fantasi megah dan investasi diri yang kuat serta dapat mengalami periode berkelanjutan pada akademik, profesional atau prestasi yang sukses dan kreatif.

Didukung oleh Ronningstam (2005) yang menyatakan bahwa narsisme yang baik mencakup kemampuan untuk mentolerir rasa bersalah,menyeimbangkan perasaan keterpisahan, keunggulan dan kebanggaan termasuk rasa syukur, kepedulian terhadap kemampuan penilaian diriyang realistis, fantasi megah yang memotivasi prestasi, kemampuan diri untuk mengendalikan rasa seseorang dari kekuasaan dan agresi yang konstruktif.

Higgs (2009) juga menyatakan bahwa perilaku narsisme pada karyawan akan sangat berpengaruh terhadap kelangsungan perusahaan dalam jangka panjang, karena perilaku narsis memenciptakan iklim yang penting untuk mencapai kinerjayang berkelanjutan, jadi perlu adanya perhatian khusus dari perusahaan untukmengembangkan sifat narsisme pada karyawan. Narsisme dalam organisasi baru pertama kali dipertimbangkan sebagai variable moderasi pada hubungan kepercayaan terhadap OCB oleh Yildiz et al. (2012). Hasil dari penelitian tersebut menjelaskan bahwa kepercayaan organisasi berpengaruh positif signifikan terhadap perilaku kewarganegaraan organisasi dan hubungan ini dimoderasi oleh narsisme dengan cara yang negatif. Narsisme menghasilkan hasil yang tidak sehat karena efek negatif sebagai moderasi. Narsisme pada dasarnya memiliki konsekuensi yang baik ketika organisasi mampu untuk mengelolanya, tetapi sebaliknya, akan berdampak buruk bagiorganisasi ketika tidak mampu untuk mengelola perilaku narsisme karyawan. 


\section{KESIMPULAN DAN SARAN}

Berdasarkan hasil penelitian dan pembahasan yang telah dilakukan tentang pengaruh variabel kepercayaan terhadap OCB yang dimoderasi oleh variabel narsisme pada karyawan UMKM kota Bengkulu, maka dapat disimpulkan bahwa penelitian ini mendukung hipotesis yang diajukan seperti, kepercayaan berpengaruh positif signifikan terhadap OCB pada karyawan UMKM di kota Bengkulu. Narsisme melemahkan kepercayaan terhadap karyawan UMKM di kota Bengkulu.

Setelah peneliti melakukan penelitian serta telah menarik kesimpulan, maka peneliti memberikan beberapa saran. Karyawan pada UMKM di kota Bengkulu sebaiknya meningkatkan kepercayaan di dalam organisasi, yaitu kepercayaan pada rekan kerja, bawahan maupun dengan atasan. Karyawan UMKM yang ada di kota bengkulu sebaiknya meningkatkan kepedulian tehadap rekan kerja dari pada bersikap individual yang dapat merugikan organisasi. UMKM sebaiknya lebih memperhatikan perilaku narsisme dari karyawannya, dan hasil negatif dari narsisme tidak boleh diabaikan.

Hasil penelitian ini menunjukkan bahwa Kepercayaan berpengaruh positif signifikan terhadap OCB dan Narsisme melemahkan kepercayaan terhadap karyawan UMKM. Hal ini mengandung implikasi agar kedepannya karyawan pada UMKM di kota Bengkulu sebaiknya meningkatkan kepercayaan di dalam organisasi dan meningkatkan kepedulian tehadap rekan kerja dari pada bersikap individual yang dapat merugikan organisasi.

Penelitian ini memiliki keterbatasan pada sampel penelitian yang hanya berada pada area Kota Bengkulu, karena keterbatasan biaya dan tenaga. Jumlah responden pada penelitian ini masih dirasa kurang. Penelitian selanjutnya diperlukan adanya pengembangan model dari model penelitian ini. Hal ini bertujuan memperbesar khasanah keilmuan. Untuk itu diperlukan penelitian lanjutan dengan pengembangan model dengan melibatkan variabel lingkungan lain, dan memperluas aspek sampel, sehingga lebih mencerminkan sampel yang lebih luas.

\section{DAFTAR PUSTAKA}

Aldag, R., \& Reschke, W. J. U. L. (2007). Employee Value Added: Measuring Discretionary Effort and Its Value to the Organization Center for Organization Effectiveness Inc.

Altuntas, S., \& Baykal, U. J. J. o. n. s. (2010). Relationship between nurses' organizational trust levels and their organizational citizenship behaviors. 42(2), 186-194.

Arshad, T., Zahra, R., Draz, U. J. A. J. o. B., \& Society. (2016). Impact of customer satisfaction on image, trust, loyalty and the customer switching behavior in conventional and Islamic banking: evidence from Pakistan. 1(3), 154-165. 
Brummelman, E., Thomaes, S., \& Sedikides, C. J. C. D. i. P. S. (2016). Separating narcissism from self-esteem. 25(1), 8-13.

Debora, D. J. J. M. d. K. (2007). Pengaruh pemberdayaan kerja dan psikologis terhadap kepercayaan organisasional dan kepuasan kerja dosen tetap perguruan tinggi swasta. 8(2), 61-71.

Ellison, N. B., \& Boyd, D. M. (2013). Sociality through social network sites. In The Oxford handbook of internet studies.

Fiona, F. (2018). Pengaruh Motivasi, Kemampuan, Persepsi Peran Terhadap Kepuasan Pegawai Di Dinas Kebudayaan Dan Pariwisata Provinsi Bengkulu. Managament Insight: Jurnal Ilmiah Manajemen, 126-139.

Gardner, D. G., \& Pierce, J. L. J. J. o. M. P. (2011). A question of false self-esteem: Organization-based self-esteem and narcissism in organizational contexts. 26(8), 682-699.

Godkin, L., \& Allcorn, S. J. H. R. D. R. (2009). Dependent narcissism, organizational learning, and human resource development. 8(4), 484-505.

Hazanah, A. (2018). The Impact of School Organizational Commitment And Transformational Leadership On Organizational Citizenship Behavior (Ocb). Universitas Mataram,

Higgs, M. J. J. o. c. m. (2009). The good, the bad and the ugly: Leadership and narcissism. 9(2), 165-178.

Knight, D. H., Choudhury, V., \& Kacmar, C. J. I. P. (2000). Trust in e-commerce vendors: a two-stage model. 54.

Organ, D. W. (1988). Organizational citizenship behavior: The good soldier syndrome: Lexington Books/DC Heath and Com.

Robbins, S. P., \& Judge, T. A. (2010). Essentials of Organizational Behavior 10th Ed: Pearson Education.

Ronningstam, E. J. P. d. (2005). Narcissistic personality disorder. 277-327.

Shao, Z. (2018). Antecedents of Trust in the Ridesharing Service: The Moderating Effect of User Experience. Paper presented at the PACIS.

Sudarma, K. J. D. S. E. (2012). Analisis kesejahteraan berbasis kinerja melalui competency dan organizational citizenship behavior (OCB) pada tenaga administrasi studi kasus pada universitas negeri semarang (UNNES).

Suhartanti, L. J. J. R. M. B. D. K. (2016). Pengaruh kontrol diri terhadap narcissistic personality disorder pada pengguna Instagram di SMA N 1 Seyegan. 5(8).

Yildiz, M. L., Öncer, A. Z. J. I. J. o. B., \& Science, S. (2012). Narcissism as a moderator of the relationship between organizational trust and organizational citizenship behaviour. 3(21). 